\title{
Peripheral Halo in a Thyroid Nodule - A Sign of Benignity
}

\author{
Bhavik Unadkat ${ }^{1}$, Suresh Vasant Phatak ${ }^{2}$, Asish Pavanan ${ }^{3}$, Prerna Anup Patwa ${ }^{4}$ \\ 1, 2,3,4 Department of Radiodiagnosis, JNMC (DMIMS), Sawangi (Meghe), Wardha, Maharashtra, India.
}

Thyroid pathology is very common in general population, even when on inspection no abnormality is detected, nodules are seen on ultrasound sonography (USG). We are describing importance of peripheral halo sign in the diagnosis of benign nodules.

Among all the endocrine gland lesions noted in India, thyroid lesion is the most common. In about $19-60 \%$ of the adult population thyroid nodules are seen; however, less than $1 \%$ of the thyroid nodules are malignant. Halo seen on ultrasound near the thyroid is considered as reliable and specific sign of benignity. ${ }^{1}$

The morphological characteristics that suggest that the thyroid nodule is benign are echogenicity of thyroid gland in that being the identical echo signal or being moderately hyperechogenic corresponding to surrounding normal thyroid tissue. The solid nodule may be accompanied by a hypoechoic halo, which represents compressed thyroid tissue, fibrous connective tissue and vessels. The cystic nodule lesion contains colloid, and this appears as a hyper-echogenic spot with "comet-tail shadowing or ring-down sign".2 The spongiform appearance on ultrasound has specificity of $99.7 \%$ for benign disease it has $98.5 \%$ negative predictive value for malignancy. ${ }^{3,4}$ At the peripheries of the nodule, complete eggshell calcification is noted. 5

A thyroid nodule with the above-mentioned characteristics is considered to be benign nodule and it does not require fine-needle aspiration cytology (FNAC) and in such patients there is neither a risk of malignancy nor a follow up USG is recommended. ${ }^{2}$ In benign thyroid lesion, there is rapid and controlled growth of thyroid cells compressing the surrounding thyroid parenchyma appearing as the echogenic rim called as sonolucent halo, on the contrary, malignant lesion has spontaneous but uncontrolled growth of the cells which lack cellular cohesion causing incomplete halo. ${ }^{6}$

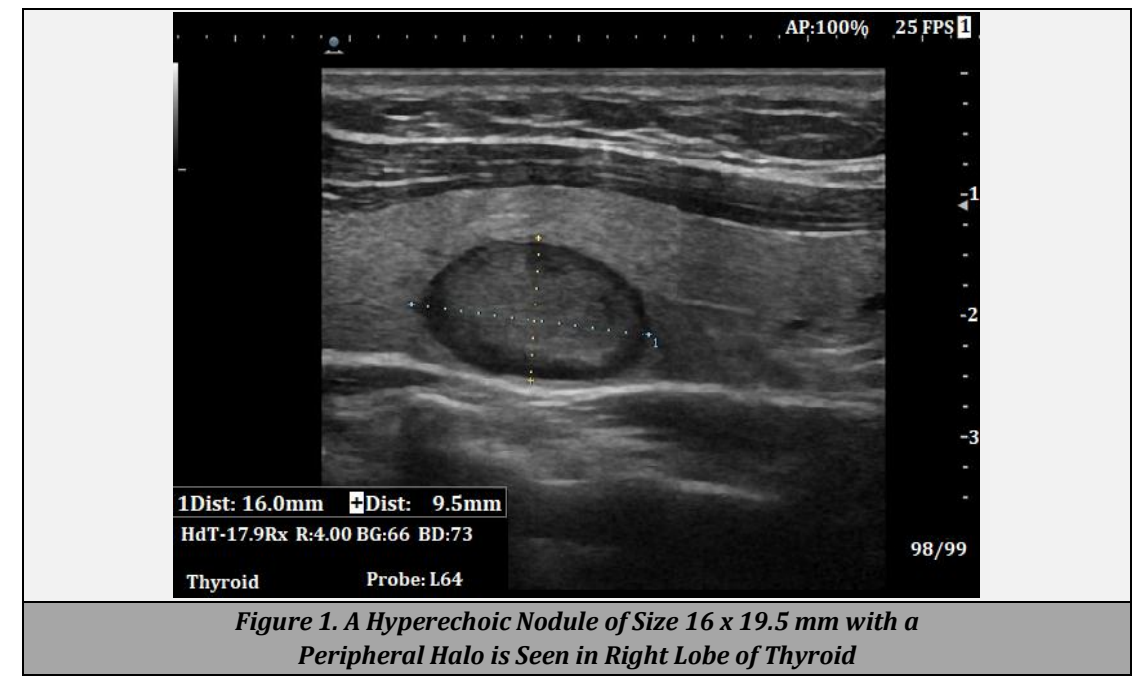

Financial or other competing interests: None.

Disclosure forms provided by the authors are available with the full text of this article at jemds.com.
Corresponding Author:

Dr. Suresh Vasant Phatak,

Department of Radiodiagnosis,

JNMC (DMIMS),

Sawangi (Meghe), Wardha,

Maharashtra, India.

E-mail: suresh_phatak@yahoo.com

DOI: $10.14260 / j e m d s / 2021 / 183$

How to Cite This Article:

Unadkat B, Phatak SV, Pavanan A, et al. Peripheral halo in a thyroid nodule - a sign of benignity. J Evolution Med Dent Sci 2021;10(11):852-853, DOI:

$10.14260 / \mathrm{jemds} / 2021 / 183$

Submission 26-10-2020,

Peer Review 20-01-2021,

Acceptance 27-01-2021,

Published 15-03-2021.

Copyright (c) 2021 Bhavik Unadkat et al. This is an open access article distributed under Creative Commons Attribution License [Attribution 4.0 International (CC BY 4.0)] 


\section{REFERENCES}

[1] Bartolotta TV, Midiri M, Runza G, et al. Incidentally discovered thyroid nodules: incidence and greyscale and colour doppler pattern in an adult population screened by real-time compound spatial sonography. Radiol Med 2006;111(7):989-98.

[2] Perros P, Boelaert K, Colley S, et al. Guidelines for the management of thyroid cancer. Clin Endocrinol (Oxf) 2014;81(Suppl 1):1-22.

[3] Moon WJ, Jung SL, Lee JH, et al. Benign and malignant thyroid nodules: US differentiation--multicenter retrospective study. Radiology 2008;247(3):762-70.
[4] Cooper DS, Doherty GM, Haugen BR, et al. Revised American Thyroid Association management guidelines for patients with thyroid nodules and differentiated thyroid cancer. Thyroid 2009;19(11):1167-214.

[5] Kim BM, Kim MJ, Kim EK, et al. Sonographic differentiation of thyroid nodules with eggshell calcifications. J Ultrasound Med 2008;27(10):1425-30.

[6] Vipul VS, Kunal GS, Chandra MS, et al. Halo sign-a helping hand to predict a thyroid nodule possibly benign. International Journal of Contemporary Medical Research 2016;3(6):1717-9. 